\section{RESOURCE CONSUMPTION CLASSES OF MACHINE TOOLS}

\author{
M. Putz ${ }^{1}$, H. J. Koriath ${ }^{1 *}$, A. P. Kuznetsov² \\ ${ }^{1}$ Fraunhofer IWU, Chemnitz, Germany \\ ${ }^{2}$ MSTU STANKIN Moscow, Russia \\ ${ }^{*}$ Corresponding author; e-mail: hans-joachim.koriath@iwu.fraunhofer.de
}

\begin{abstract}
From the point of view manufacturer, machine tools fulfil technological requirements of manufacturing processes for part geometrical dimensions, shaping and material property change. Main machine tool functions are axis motions with sufficient power reserve drives to technological process loads, consuming energy. Participation of manufacturing systems and processes for sustainable life in industrial applications and limiting earth warming up is required. This paper is responding to a scientific demand in setting development trends for manufacturing systems, processes and environment. Here a scientific question arises: which technological requirements and machine functionalities to machine tool characteristics lead to their lowest resource consumption / losses and part manufacturing costs? The machine tool manufacturer methodology is following a relation and dependency analysis, combined with functional synthesis and resource optimization. The machine tool user applies the key performance indicator "Overall Equipment Effectiveness OEE" integrates efficiency values for productivity, availability, quality, targeting minimal part manufacturing costs.
\end{abstract}

Keywords:

Machine tool; Energy; Resource; Efficiency; Costs

\section{INTRODUCTION}

Machine tools fulfil technological requirements of manufacturing processes for part shaping and material property change. Here a scientific question is arising on sustainability: which technological requirements and machine functionalities to machine tool characteristics lead to their lowest resource consumption / losses and part manufacturing costs?

[Grigor'ev 2014], [Kuznetsov 2016_1] introduce a resource consumption classification based on relevant physical relations and efficiency match between the real and target values. Paper [Götze 2012] proposes an integrated approach for the evaluation of machine tools consisting of methodological proposals for the measurement of energy consumption, modeling of energy flows and simulative analysis of the energy saving potentials as well as an energy-oriented life-cycle costing concept. The existing energy consumption models were classified into three categories: 1) the linear type of cutting energy consumption model based on material remove rate, 2) detailed parameter type of cutting energy consumption correlation models and 3 ) process oriented machining energy consumption model. [Zhou 2016] Three categories of energy-efficient and environmentally strategies include optimization of process control, the selection of optimum machine tools and processes and technologies regarding machine tool design. [Yoon 2015] The reference process method contains the measurement of a machine tool's energy consumption for a predefined utilization profile in all operational states (off, standby, ready, processing). Other test methods like reference part method, specific energy consumption method and component benchmark method have a lower multi-criterion ranking. [Schudoleit 2015]

The "Total Energy Efficiency Index for machine tools" presents a metric that matches all criteria to promote the development of the ISO 14955 series and to quantify the design of machine tools regarding energy efficiency based on the respective assembly of components. The applicability of the metric is proven in a practical case study on a turning machine. [Schudoleit 2016] The machine tool manufacturer methodology is following a relation and dependency analysis, combined with functional synthesis and resource optimization. [ISO 14955-1:2017], [VDI 2206:2004] The Standard [GOST R 54430-2011] defines energy-efficiency classes for machine tools, based on process time assessment. An optimum workpiece setting position exists for a $20 \%$ less energy consumption of feed drive systems, comprising friction, motor and amplifier losses along each motion axis. [Sato 2018]

The scientific demand in setting development trends for manufacturing systems, processes and environment is preparing in the Progress Report on STC-M Keynote Paper 2020 "Energy Efficient Machine Tools". [Denkena 2018]

Currently, there is only a conditional classification of metalcutting machine tools based on power (not energy) consumption and related converter efficiency, but there's not even a standard, but there are names for turning, drilling, grinding, etc. [Kuznetsov 2016_2], [DIN 8580:200309].

Except [Kuznetsov 2018], [Grigor'ev 2014], [Kuznetsov 2016_1], [Kuznetsov 2017], there is no method of resource 
efficiency evaluation, which is defined as the degree of use of a resource (material, energy and information), and the studies are mainly aimed at assessing energy efficiency as a way of processing the measured power, current, total voltage as output and input power ratio. The method for assessing the resource efficiency of different types of metalworking requires consideration of the degree of resource utilization as a single system of transformation and transformation of all types of resources.

The machine tool user applies the key performance indicator "Overall Equipment Effectiveness OEE" integrates efficiency values for productivity, availability, quality, targeting minimal part manufacturing costs. In fact, the OEE-Index, in the methods of its assessment and implementation proposed by various authors [Gamberini 2017], is a product of three probabilities of events, each of which is equal to the ratio of the time of completion of the event to the total time of the event:

$O E E-$ Index $=\frac{B}{A} \times \frac{D}{C} \times \frac{F}{E}=\frac{F}{A} \quad(1)$ or
$O E E-$ Index $=\frac{F+\delta E+\delta D}{F+\delta E+\delta D+\delta B} \times \frac{F+\delta E}{F+\delta E+\delta D} \times \frac{F}{F+\delta E}$

where $E=F+\delta E ; D=E ; C=D+\delta D ; B=C ; A=B+\delta B$; $A=F+\delta E+\delta D+\delta B$. Therefore,

$O E E-$ Index $=\frac{F}{A}=\frac{F}{F+\delta E+\delta D+\delta B}$

Since in all cases and methods of OEE-Index estimation [ISO 22400-2:2014], [Gamberini 2017] the constant value is the considered or set time period, the variable components are the gradation of the number of event groups and types of time losses within each group of such events.

$O E E-$ Index $=\frac{A P T}{P B T} \times \frac{P R I * P Q}{A P T} \times \frac{G Q}{P Q}=\frac{P R I * G Q}{P B T} ;(4)$

APT - Actual production time (A); AUPT - Actual unit processing time (D); PRI - Planned run time per item; PBT - Planned busy time (C); GQ — Good quantity (F); PQ Produced quantity (E); OT - Operating time (B).

Thus, for example, fig. 3 in [ISO 22400-2:2014] the reference time is the basic time, but in calculations all of the OEE-index the PBT, PRI and APT are used, and the time losses are outside the cycle losses. But the OEE value In Appendix B of [ISO 22400-2:2014] is an alternative to the OEE-index.

The difference between the formation and internal content of the comparison bases, the content of the components and the method of calculation of the indicators Availability A, Efficiency $P$ and Quality $Q$ (\% waste) is obvious. In these cases [Gamberini 2017], [Varisco 2018] (OEE and OEEindex), the time losses are essentially attributed to different comparison bases. It is obvious that the method of considering the operating time of equipment (technological or production process) as a system and its elements depends on the content and essence of the evaluation of indicators. Therefore, in the proposed method of efficiency assessment it is considered as a single system, the structure of which consists of a single set of elements, the change of which is substantially occurs on the same principles.

Therefore, the main difference between the proposed classification (which does not exist, there is an evaluation method) and the OEE-Index is in the allocation of their effectiveness classes (as an integral indicator), which is understood as the degree of resource use (energy - energy efficiency), time (productivity efficiency and OEE), speed of part property conversion (manufacturing performance), economic efficiency etc.

\section{METHODOLOGY FOR CONSUMPTION ANALYSIS}

RESOURCE

A „classification method" separates different machine tools in to classes or groups based on "selection criteria".

"Selection criteria" for resource efficiency are proportions between useful / output and consumed / input resource quantities.

The recommended methodology bases on a resource consumption analysis (2.1), a classification of machine tools (2.2), types of resource efficiencies and methods for their assessment (3).

\subsection{Resource consumption analysis}

A plurality of methods for machining and forming parts and products, processes and equipment is known for their implementation. Modern tendencies towards improvements in productivity, accuracy, reliability, flexibility, efficiency and effectiveness influence both the production and processing equipment and machinery systems. Architecture of technological process, physical processes and part properties interactions is shown in fig.1.

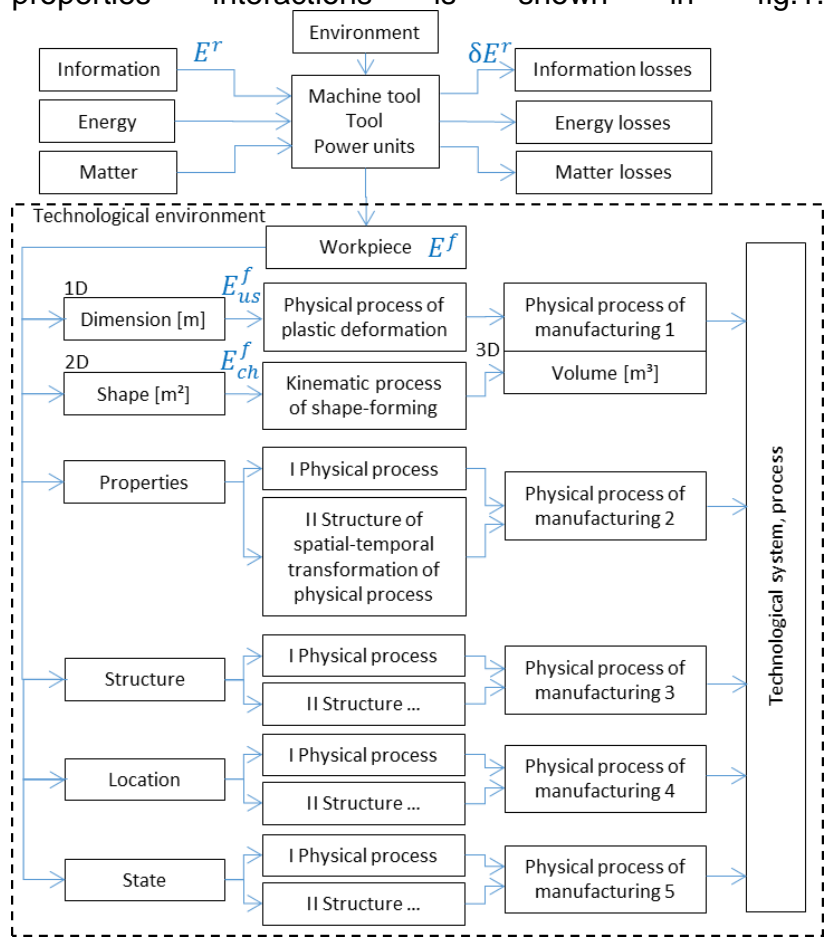

Fig. 1: Architecture of technological process, physical processes and part properties interactions.

System elements, ensuring the forming of part dimension (physical process, implemented by the tool) and the forming of part surfaces (physical process of surface forming, implemented by operating elements of the machine), are highlighted here. Other characteristics and parameters, that describe the information image of the part, are formed by other methods of processing in accordance with the technological image of the part. Technological process is performed through the manufacturing equipment with use of material, energy, information. The result of the technological process is the product, which shall meet the customer's expectations. Consequently, the manufacturing process consists of two parts: a set of items of physical processes I (the physical process of plastic deformation, which defines the size, is shown) and its corresponding set of structures of spatial temporal transformation II of the physical process (kinematic process of forming, which defines the desired shape of the part, is shown). 
In order to achieve the desired properties of the part (such as hardness) other physical processes are needed (other than the plastic deformation operations) and their spatial temporal transformation. In this case under the production process we understand the process of interrelated conversion of matter, energy and information. The physical equivalence of resource type change and form transformations are applied to real processes. Resource losses during the transformation from one form $\mathrm{k}$ to another form $n$ consist of internal losses and transformation losses (dissipation). Resource losses apply during the transformation from one form $\mathrm{k}$ to another form $\mathrm{n}$ and during exchange from one form $\mathrm{k}$ to another form $\mathrm{n}$. For instance, mechanical energy is the energy of plastic deformations or displacement or inter-crystal or interatomic interactions. Potential energy is the energy of elastic deformations.

The unified methodological approach to the evaluation of resource efficiency of machine tools allows to consider them as an energy-information model (see fig. 1), in which the transformation of any forms and types of energy, matter and information takes place. [Kuznetsov 2017] Then the concept of efficiency is considered as a relative efficiency and characterizes the degree of use of any resource. Therefore, the ratio of volumes (energies, capacities, material, information, time, etc.) at the output of $E_{j}$ and at the input of $E_{i}$ is an assessment of the efficiency $E_{e}$. In all cases the numerator of any resource use determines its ideal, conditioned by the applied physical process or phenomenon $E^{f}$ (nominal or theoretical), and the denominator of its actual $E^{r}$ (real) value or value:

$E_{e}=\frac{E_{j}}{E_{i}}=\frac{E_{\text {out }}}{E_{\text {in }}}=\frac{E^{f}}{E^{r}}(5)$

The unity of phenomenological laws, which describe the processes of transformation of various forms and types of energy, matter and information determines their independence from the design, layout, technical and technological execution of metal-cutting machines. Therefore, as with any efficiency factor, the overall efficiency of the system is equal to the product of the components $\prod_{q=1}^{k} E_{e}^{k}$ and does not depend on the nature of the efficiency factor itself. Then the integral indicator of resource efficiency $E_{r e}$ will be equal to the product of the efficiency of the use of matter $E_{e}^{m}$, energy $E_{e}^{e}$ and information $E_{e}^{i}$ :

$E_{r e}=E_{e}^{e} \times E_{e}^{m} \times E_{e}^{i}$

and are estimates of the energy efficiency of $E_{e}^{e}$, performance of $E_{e}^{m}$ and accuracy of $E_{e}^{i}$. Each resource component, according to the model in fig.1, can be represented as a physical process of $E_{u s}^{f}$ application and $E_{c h}^{f}$ provisioning resource and/or kinematic changes in position of physical processes of application (i.e. the resource required to change the position in the physical process vector space). Then expression (2) will be written in the form:

$E_{r e}=\left(\frac{E_{u s}^{f}+E_{c h}^{f}}{\left(E_{u s}^{f}\right)^{r}+\left(E_{c h}^{f}\right)^{r}}\right)_{e}^{e} \times\left(\frac{E_{u s}^{f}+E_{c h}^{f}}{\left(E_{u s}^{f}\right)^{r}+\left(E_{c h}^{f}\right)^{r}}\right)_{e}^{m} \times\left(\frac{E_{u s}^{f}+E_{c h}^{f}}{\left(E_{u s}^{f}\right)^{r}+\left(E_{c h}^{f}\right)^{r}}\right)_{e}^{i}$

(7)

In turn, each of the components of the multipliers in (7) can be written:

$U_{e}=\frac{E_{u s}^{f}+E_{c h}^{f}}{\left(E_{u s}^{f}\right)^{r}+\left(E_{c h}^{f}\right)^{r}}=\frac{E_{u s}^{f}}{\left(E_{u s}^{f}\right)^{r}} \times \frac{E_{u s}^{f}+E_{c h}^{f}}{E_{u s}^{f}} \times \frac{\left(E_{u s}^{f}\right)^{r}}{\left(E_{u s}^{f}\right)^{r}+\left(E_{c h}^{f}\right)^{r}}=U_{u s}^{f r} \times$ $U_{\text {us }}^{f c h} \times U_{\text {usch }}^{\text {fr }}$ (8)

where $\left(E_{u s}^{f}\right)^{r}$ is the input resource required for the physical process and other related processes, including those of other physical nature, that ensure the execution of the physical process. $\left(E_{c h}^{f}\right)^{r}$ is the input resource required to change the position in the space of the physical process vector and other related processes, including other physical nature, providing the process of changing the position in the space of the physical process vector. $U_{u s}^{f r}$ describes the efficiency of the resource of the physical process of application. $U_{u s}^{f c h}$ - describes the efficiency of the use of physical resources for the physical process of application. $U_{u s c h}^{f r}$ - describes the real efficiency of the resource of the physical process of application.

Then (7) will be written in the form:

$$
\begin{aligned}
& E_{r e}=\left(U_{u s}^{f r} \times U_{u s}^{f c h} \times U_{u s c h}^{f r}\right)_{e}^{e} \times\left(U_{u s}^{f r} \times U_{u s}^{f c h} \times U_{u s c h}^{f r}\right)_{e}^{m} \times \\
& \left(U_{u s}^{f r} \times U_{u s}^{f c h} \times U_{u s c h}^{f r}\right)_{e}^{i} \text { (9) }
\end{aligned}
$$

Consequently, a basic set of performance indicators can be derived from (8) and (9) (see table 1).

\begin{tabular}{|c|c|c|}
\hline Efficiency & Formula & Range \\
\hline Potential & $\left(U_{u s}^{f c h}\right)^{-1}=\frac{E_{u s}^{f}}{E_{u s}^{f}+E_{c h}^{f}}$ & $0 \div 1$ \\
\hline $\begin{array}{l}\text { Resource } \\
\text { usage }\end{array}$ & $U_{u s}^{f r}=\frac{E_{u s}^{f}}{\left(E_{u s}^{f}\right)^{r}}$ & $0 \div 1$ \\
\hline Processes & $U_{u s}^{c h}=\frac{E_{c h}^{f}}{E_{u s}^{f}}$ & $0 \div \infty$ \\
\hline $\begin{array}{l}\text { Process- } \\
\text { supporting } \\
\text { resources }\end{array}$ & $U_{c h}^{f}=\frac{E_{c h}^{f}}{E_{c h}^{f}+\left(\Delta E_{k, n}\right)_{c h}^{f}}$ & $0 \div 1$ \\
\hline $\begin{array}{l}\text { Resource } \\
\text { applications }\end{array}$ & $U_{\Delta}^{f}=\frac{E_{u s}^{f} \times\left(E_{c h}^{f}+\left(\Delta E_{k, n}\right)_{c h}^{f}\right)}{E_{u s}^{f}+\left(\Delta E_{k, n}\right)_{u s}^{f}}$ & $0 \div \infty$ \\
\hline $\begin{array}{l}\text { Applications } \\
\text { of process- } \\
\text { supporting } \\
\text { resources }\end{array}$ & $U_{\Delta}^{c h}=\frac{E_{c h}^{f} \times\left(E_{c h}^{f}+\left(\Delta E_{k, n}\right)_{c h}^{f}\right)}{E_{u s}^{f}+\left(\Delta E_{k, n}\right)_{u s}^{f}}$ & $0 \div \infty$ \\
\hline Resource & $U_{u s c h}^{f r}=$ & \\
\hline $\begin{array}{l}\text { transfor- } \\
\text { mations }\end{array}$ & $\overline{1+\frac{E_{c h}^{f}}{E_{u s}^{f}} \times \frac{E_{c h}^{f}+\left(\Delta E_{k, n}\right)_{c h}^{f}}{E_{c h}^{f}} \times \frac{E_{u s}^{f}}{E_{u s}^{f}+\left(\Delta E_{k, n}\right)_{u s}^{f}}}$ & $0 \div 1$ \\
\hline Actual (real) & $U_{u s c h}^{f r}=\frac{\left(E_{u s}^{f}\right)^{r}}{\left(E_{u s}^{f}\right)^{r}+\left(E_{c h}^{f}\right)^{r}}$ & $0 \div 1$ \\
\hline $\begin{array}{l}\text { Resource } \\
\text { saturation }\end{array}$ & $\begin{array}{l}U_{u s c h}^{f}=U_{u s}^{f r} \times U_{u s c h}^{f r}= \\
\frac{E_{u s}^{f r}}{\left(E_{u s}^{f}\right)^{r}+\left(E_{c h}^{f}\right)^{r}}\end{array}$ & $0 \div 1$ \\
\hline $\begin{array}{l}\text { Increasing } \\
\text { resource } \\
\text { saturation }\end{array}$ & $\left(U_{u s}^{f c h}\right)^{-1} \times\left(U_{u s c h}^{f r}\right)^{-1}=U_{r}^{f}$ & $0 \div \infty$ \\
\hline $\begin{array}{l}\text { Integral } \\
\text { efficiency }\end{array}$ & $U_{e}=U_{u s}^{f r} \times U_{u s}^{f c h} \times U_{u s c h}^{f r}$ & $0 \div 1$ \\
\hline
\end{tabular}

Tab. 1: Basic set of performance indicators.

The expression of efficiency in this form (7), (8) is a universal method of evaluation, so it is applicable to the analysis of any machine tools, including those performing simultaneous conversion of several types of resources. This method makes it possible to compare the degree of perfection of ongoing processes, which is due to the possibility of taking into account all types of losses both in the transfer (exchange, transformation) of energy, matter and information from the source to the transforming 
mechanisms and devices, and in the transformation into them (fig. 2).

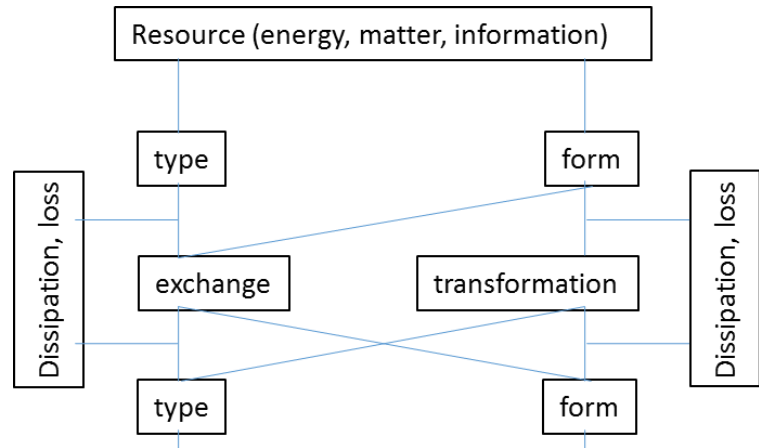

Physical process (energy, matter, information)

Fig. 2: Resource transformation scheme.

That's why you can write a general expression of resource losses:

$\Delta E_{k, n}=\delta E_{k, k}+\delta E_{k, n}(10)$

where $\delta E_{k, k}$ - internal losses; transition (dissipation) losses $\delta E_{k, n}$ - and when converting one form of resource $\mathrm{k}$ to another form or form $\mathrm{n}$. Then (8) can be written:

$U_{e}=\frac{E_{u s}^{f}+E_{c h}^{f}}{\left(E_{u s}^{f}\right)^{r}+\left(E_{c h}^{f}\right)^{r}}=\frac{E_{u s}^{f}+E_{c h}^{f}}{E_{u s}^{f}+\left(\Delta E_{k, n}\right)_{u s}^{f}+E_{c h}^{f}+\left(\Delta E_{k, n}\right)_{c h}^{f}}=U_{u s}^{f r} \times U_{u s}^{f c h} \times$

$U_{u s c h}^{f r}=\frac{1}{1+\frac{\left(\Delta E_{k, n}\right)_{u s}^{f}}{E_{u s}^{f}}} \times \frac{1+\frac{E_{c h}^{f}}{E_{u s}^{f}}}{1} \times \frac{1}{1+\frac{E_{c h}^{f}}{E_{u s}^{f}} \times \frac{E_{c h}^{f}+\left(\Delta E_{k, n}\right)_{c h}^{f}}{E_{c h}^{f}} \times \frac{E_{u s}^{f}}{\left(E_{u s}^{f}+\left(\Delta E_{k, n}\right)_{u s}^{f}\right)}}$

(11)

\subsection{Classification of machine tools by resource consumption}

Expressions (11) and (9) make it possible to evaluate the integral indicator of the level of resource efficiency of machines, as the values included in it describe the energy information processes of their transformation. In this case, the basis is the normalized value of the physical process itself and the vector of its spatial change.

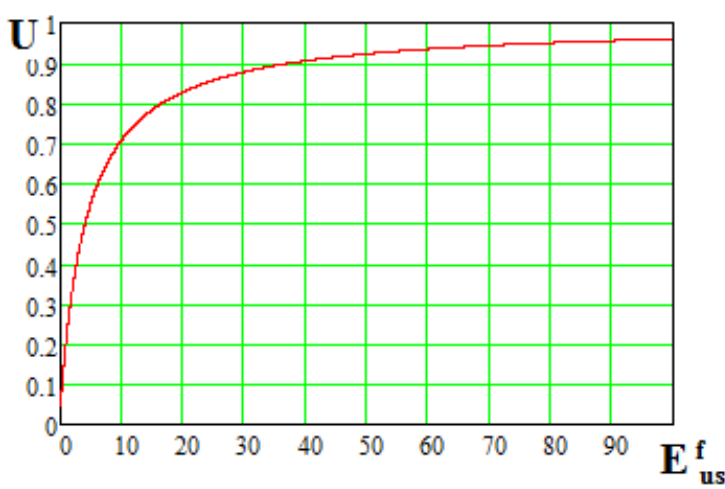

Fig 3: Graph of changes in resource efficiency.

Analyzing the equation (11) we get a typical characteristic graph of the resource efficiency dependence on its physical parameter of the resource application process, shown in fig. 3. Taking into account the similarity of the applied method of estimation, the character of the change of efficiency can be suggested the grading of machine tool classes by the level of resource efficiency of table 2 :
Tab. 2: Grading of machine tools by resource efficiency classes.

\begin{tabular}{|l|l|l|}
\hline $\begin{array}{l}\text { Resource } \\
\text { efficiency } \\
\text { class }\end{array}$ & $\begin{array}{l}\text { Name of resource } \\
\text { efficiency class }\end{array}$ & $\begin{array}{l}\text { The value of } \\
\text { resource } \\
\text { efficiency } E_{\mathrm{e}}\end{array}$ \\
\hline 1 & Extremely high & $1,00-0,95$ \\
\hline 2 & Very high & $0,949-0,9$ \\
\hline 3 & High & $0,89-0,85$ \\
\hline 4 & Above average & $0,849-0,8$ \\
\hline 5 & Average & $0,799-0,75$ \\
\hline 6 & Below average & $0,749-0,65$ \\
\hline 7 & Low & $0,649-0,5$ \\
\hline
\end{tabular}

In addition, the number and variety of specific indicators of performance levels (see table 1) can be obtained based on the diversity of elements of the system (fig. 1). The fractionality of the representation of species and forms of resources and their elements of transformation, the relationship between which is based on the representation and methods of transformation of the expression (8) within the framework of the accepted to consider the system, structure and their elements.

Similarly, it is proposed to introduce the classes of each of three components of $U_{u s}^{f r} \times U_{u s}^{f c h} \times U_{u s c h}^{f r}$ effects in total dependence (8) for each resource type $E_{r e}=E_{e}^{e} \times E_{e}^{m} \times E_{e}^{i}$. Then we obtain the integral indices of machine classes for all resource efficiency indicators (table 3).

Tab. 3: Machine classes according to the integral indicator of resource efficiency.

\begin{tabular}{|c|c|c|c|c|c|}
\hline $\begin{array}{l}\text { Res } \\
\text { ourc } \\
\text { e } \\
\text { effici } \\
\text { ency } \\
\text { clas } \\
\text { s }\end{array}$ & $\begin{array}{l}\text { Name of } \\
\text { resource } \\
\text { efficiency } \\
\text { class }\end{array}$ & \begin{tabular}{l} 
The \\
value \\
of \\
energy \\
efficien \\
cy \\
class \\
\multicolumn{1}{c}{$\mathrm{E}_{\mathrm{e}}^{\mathrm{e}}$}
\end{tabular} & $\begin{array}{l}\text { The } \\
\text { value o } \\
\text { producti } \\
\text { vity } \\
\text { efficienc } \\
\text { y class } \\
\qquad E_{e}^{m}\end{array}$ & $\begin{array}{l}\text { The } \\
\text { value } \\
\text { of } \\
\text { accura } \\
\text { cy } \\
\text { efficien } \\
\text { cy } \\
\text { class } \\
\quad \mathrm{E}_{\mathrm{e}}^{\mathrm{i}} \text {. }\end{array}$ & $\begin{array}{l}\text { The } \\
\text { value } \\
\text { of } \\
\text { resourc } \\
\text { e } \\
\text { efficien } \\
\text { cy } \\
\text { class } \\
\text { E }_{\text {re }}\end{array}$ \\
\hline 1 & $\begin{array}{l}\text { Extremely } \\
\text { high }\end{array}$ & $\begin{array}{l}1,00- \\
0,95\end{array}$ & $\begin{array}{l}1,00 \\
0,95\end{array}$ & $\begin{array}{l}1,00- \\
0,95\end{array}$ & $\begin{array}{l}1,00- \\
0,86\end{array}$ \\
\hline 2 & Very high & $\begin{array}{l}0,949- \\
0,9\end{array}$ & $\begin{array}{l}0,949 \\
0,9\end{array}$ & $\begin{array}{l}0,949- \\
0,9\end{array}$ & $\begin{array}{l}0,85- \\
0,73\end{array}$ \\
\hline 3 & High & $\begin{array}{l}0,899- \\
0,85\end{array}$ & $\begin{array}{l}0,899 \\
0,85\end{array}$ & $\begin{array}{l}0,899- \\
0,85\end{array}$ & $\begin{array}{l}0,72- \\
0,62\end{array}$ \\
\hline 4 & $\begin{array}{l}\text { Above } \\
\text { average }\end{array}$ & $\begin{array}{l}0,849- \\
0,8\end{array}$ & $\begin{array}{l}0,849 \\
0,8\end{array}$ & $\begin{array}{l}0,849- \\
0,8\end{array}$ & $\begin{array}{l}0,61- \\
0,52\end{array}$ \\
\hline 5 & Average & $\begin{array}{l}0,799- \\
0,75\end{array}$ & $\begin{array}{l}0,799 \\
0,75\end{array}$ & $\begin{array}{l}0,799- \\
0,75\end{array}$ & $\begin{array}{l}0,51- \\
0,43\end{array}$ \\
\hline 6 & $\begin{array}{l}\text { Below } \\
\text { average }\end{array}$ & $\begin{array}{l}, 749- \\
0,65\end{array}$ & $\begin{array}{l}749 \\
0,65\end{array}$ & $\begin{array}{l}749- \\
0,65\end{array}$ & $\begin{array}{l}0,42- \\
0,28\end{array}$ \\
\hline 7 & Low & $\begin{array}{l}0,649- \\
0,5\end{array}$ & $\begin{array}{l}0,649 \\
0,5\end{array}$ & $\begin{array}{l}0,649- \\
0,5\end{array}$ & $\begin{array}{l}0,27- \\
0,13\end{array}$ \\
\hline
\end{tabular}

The methodology we propose for the already known OEEIndex can be used to grade machine tool classes according to this private performance indicator. It is important, that manufacturing, quality is a measure of excellence or a state of being free from defects, deficiencies and significant variations. It is brought about by strict and consistent commitment to certain standards that achieve uniformity of a product in order to satisfy specific customer or user requirements. The good quantity $\mathrm{GQ}$ is the produced 
quantity that meets quality requirements. The quality rate is the relationship of the good quantity to the produced quantity.

Similar to table 3, we introduce seven classes for OEEIndex, manufacturing costs and partially for performance, availability, part quality proposed in table 4 . Class $\mathrm{N}^{\circ} 1$ defines target values for minimal resource consumption and highest resource efficiency.

Tab. 4: OEE classes partially for performance, availability, part quality.

\begin{tabular}{|l|ll|ll|ll|ll|}
\hline $\begin{array}{l}\text { OEE } \\
\text { class } \\
\mathrm{N}^{\circ}\end{array}$ & $\begin{array}{l}\text { Perfor- } \\
\text { mance } \\
\mathrm{P}\end{array}$ & $\begin{array}{l}\text { Avail- } \\
\text { ability } \\
\mathrm{A}\end{array}$ & $\begin{array}{l}\text { Part } \\
\text { quality } \\
\mathrm{Q}\end{array}$ & $\begin{array}{l}\text { OEE- } \\
\text { Index } \\
=\end{array}$ \\
\hline 1 & $\begin{array}{l}1,0 \\
0,95\end{array}$ & - & $\begin{array}{l}1,0 \\
0,95\end{array}$ & - & $\begin{array}{l}1,0 \\
0,95\end{array}$ & - & \multicolumn{2}{|l|}{$\begin{array}{l}1,00 \\
-0,86\end{array}$} \\
\hline 2 & 0,949 & - & 0,949 & - & 0,949 & - & 0,85 & - \\
& 0,9 & & 0,9 & & 0,9 & & 0,73 & \\
\hline 3 & 0,899 & - & 0,899 & - & 0,899 & - & 0,72 & - \\
& 0,85 & & 0,85 & & 0,85 & & 0,62 & \\
\hline 4 & 0,849 & - & 0,849 & - & 0,849 & - & 0,61 & - \\
& 0,8 & & 0,8 & & 0,8 & & 0,52 & \\
\hline 5 & $0,799-$ & 0,799 & - & 0,799 & - & 0,51 & - \\
& 0,75 & & 0,75 & 0,75 & & 0,43 & \\
\hline 6 & $0,749-$ & $0,749-$ & 0,749 & - & 0,42 & - \\
& 0,65 & & 0,65 & 0,65 & & 0,28 & \\
\hline 7 & 0,649 & - & $0,649-$ & 0,649 & - & 0,27 & - \\
& 0,5 & & 0,5 & 0,5 & & 0,13 & \\
\hline
\end{tabular}

\section{TYPES OF RESOURCE EFFICIENCIES AND METHODS FOR THEIR ASSESSMENT}

Ressource efficiency is the extent of the use of any resource. Resource efficiency is the extent to which a resource (energy, time, money, material, air, liquid, etc.) is used.

Main resources for machine tools are material properties (load), power reserve and motion profile resulting in energy consumption. Main technological requirements define the manufacturing method, process productivity, system availability, part quality resulting in manufacturing costs.

All of the following performance assessment methods are based on the methodology and method of evaluation of expressions (7) - (11) and their constituent elements, in conjunction with the existing evaluations of the elements considered in these expressions.

\subsection{Energy consumption $E_{e}^{e}$}

Energy consumption $E_{e}^{e}$ is the integral of power consumption over time against process loads

$W_{C}=\int P_{C} \times d t ;(12)$

where $\mathrm{W}_{\mathrm{C}}$ - cutting energy, $P_{C}-$ cutting power, $\mathrm{t}$ - process time. A relation and dependency analysis overview between main resources and technological requirements is presented in table 5.

Tab. 5: Relation and dependency analysis overview between main resources and technological requirements.

\begin{tabular}{|l|l|l|l|l|}
$\begin{array}{l}\text { Technolo } \\
\text { gical } \\
\text { requireme } \\
\text { nts }\end{array}$ & $\begin{array}{l}\text { Material } \\
\text { property } \\
(\text { load) }\end{array}$ & $\begin{array}{l}\text { Power } \\
\text { reserve } \\
(\mathrm{P})\end{array}$ & $\begin{array}{l}\text { Motion } \\
\text { profile } \\
(\mathrm{t})\end{array}$ & $\begin{array}{l}\text { Energy } \\
\text { consumpti } \\
\text { on }(\mathrm{W})\end{array}$ \\
\hline
\end{tabular}

\begin{tabular}{|c|c|c|c|c|}
\hline $\begin{array}{l}\text { Method, } \\
\text { Standard }\end{array}$ & $\begin{array}{l}\text { Technolo- } \\
\text { gy, } \\
\text { [DIN } \\
8580: 2003 \\
-09]\end{array}$ & $\begin{array}{l}\text { Mechatro- } \\
\text { nic design, } \\
\text { [VDI } \\
2206: 2004 \\
\text { ] }\end{array}$ & $\begin{array}{l}\text { Drive, } \\
\text { sensor, } \\
\text { control, } \\
\text { [VDI/VDE } \\
3547: 2003 \\
\text { ], [ISO } \\
22400- \\
2: 2014]\end{array}$ & $\begin{array}{l}\text { Resource } \\
\text { classifica- } \\
\text { tion, [DIN } \\
8580: 200 \\
3-09]\end{array}$ \\
\hline $\begin{array}{l}\text { Technolo } \\
\text { gical } \\
\text { performan } \\
\text { ce }\end{array}$ & $\begin{array}{l}\text { Shape } \\
\text { removal / } \\
\text { generation } \\
\text { rate per } \\
\text { material } \\
\text { strength }\end{array}$ & $\begin{array}{l}\text { Process } \\
\text { power per } \\
\text { part } \\
\text { volume } \\
\text { change }\end{array}$ & $\begin{array}{l}\text { velocity } \\
\text { profile } \\
\text { over } \\
\text { process } \\
\text { load }\end{array}$ & $\begin{array}{l}\text { Resource } \\
/ \text { energy } \\
\text { consump- } \\
\text { tion per } \\
\text { part }\end{array}$ \\
\hline $\begin{array}{l}\text { Manufact } \\
\text { uring } \\
\text { system } \\
\text { availability }\end{array}$ & $\begin{array}{l}\text { Resource } \\
\text { life time } \\
\text { reserve } \\
\text { per } \\
\text { process } \\
\text { load }\end{array}$ & $\begin{array}{l}\text { Machine } \\
\text { tool } \\
\text { geometry, } \\
\text { dimension }\end{array}$ & $\begin{array}{l}\text { Axes } \\
\text { position, } \\
\text { orientation } \\
\text { per } \\
\text { kinematic } \\
\text { chain }\end{array}$ & $\begin{array}{l}\text { Compo- } \\
\text { nent } \\
\text { energy } \\
\text { efficiency }\end{array}$ \\
\hline $\begin{array}{l}\text { Part } \\
\text { quality }\end{array}$ & $\begin{array}{l}\text { Geometry } \\
\text { and } \\
\text { surface } \\
\text { quality }\end{array}$ & $\begin{array}{l}\text { System } \\
\text { stiffness, } \\
\text { tool wear } \\
\text { per shape } \\
\text { and } \\
\text { material } \\
\text { property } \\
\text { change }\end{array}$ & $\begin{array}{l}\text { Contour } \\
\text { control } \\
\text { deviation, } \\
\text { Eigen } \\
\text { frequency }\end{array}$ & $\begin{array}{l}\text { Energy } \\
\text { consump- } \\
\text { tion per } \\
\text { quality } \\
\text { value }\end{array}$ \\
\hline $\begin{array}{l}\text { Manufact } \\
\text { uring } \\
\text { costs (C) }\end{array}$ & $\begin{array}{l}\text { Process } \\
\text { effective- } \\
\text { ness }\end{array}$ & $\begin{array}{l}\text { Machine } \\
\text { and tool } \\
\text { life time } \\
\text { costs }\end{array}$ & $\begin{array}{l}\text { Part } \\
\text { manufac- } \\
\text { turing time }\end{array}$ & $\begin{array}{l}\text { Value } \\
\text { creation } \\
\text { per } \\
\text { energy } \\
\text { costs }\end{array}$ \\
\hline
\end{tabular}

The energy of the physical process is equal to the work of the generalized force $F_{i}$ at the generalized distance $L_{i}$ :

$E_{i}=F_{i} \times L_{i} ;(13)$

where the generalized force for physical processes (according to fig. 1) is determined by the laws of the physical phenomenon of the process (table 6).

\section{Tab. 6: Laws of the physical phenomenon of the process.}

\begin{tabular}{|l|l|l|}
\hline $\begin{array}{l}\text { Force name of } \\
\text { the physical } \\
\text { phenomenon }\end{array}$ & $\begin{array}{l}\text { Generalized } \\
\text { force }\end{array}$ & Parameters \\
\hline Gravity & $G=m \times g$ & $\begin{array}{l}\text { Mass } \\
\text { acceleration of free } \\
\text { fall g }\end{array}$ \\
\hline Mechanical & $F=m \times a$ & $\begin{array}{l}\text { Mass } \\
\text { acceleration a, a, } \\
\text { angular rotation } \\
\text { speed } \omega \text {, radius } r\end{array}$ \\
\hline Electrical & $U=I \times R$ & $\begin{array}{l}\text { Current I, } \\
\text { resistance R }\end{array}$ \\
\hline Magnetic & $F_{M}=B \times \Phi$ & $\begin{array}{l}\text { Magnetic induction } \\
\text { B, magnetic flux } \Phi\end{array}$ \\
\hline Thermal & $Q=T \times X$ & $\begin{array}{l}\text { Temperature } \mathrm{T}, \\
\text { thermal resistance } \\
\mathrm{X}\end{array}$ \\
\hline
\end{tabular}

Technological process performance is a function of material property, power reserve and motion profile. Technological productivity depends mainly on shape removal or generation rate per work piece material strength and hardness. In mechanics of materials, the strength of a material is its ability to withstand an applied load without 
failure or plastic deformation. The field of strength of materials deals with forces and deformations that result from their acting on a material. A load applied to a mechanical member will induce internal forces within the member called stresses when those forces are expressed on a unit basis. An elastic modulus is a quantity that measures an object or substance's resistance to being deformed elastically (i.e., non-permanently) when a stress is applied to it. Hardness is a measure of the resistance to localized plastic deformation induced by either mechanical indentation or abrasion. Some materials are harder than others and used as tool materials. Technological productivity depends on material removal or generation rate MRR per material strength and hardness.

$M R R=v \times f \times a_{P} ;(14)$ where $v$ - cutting speed; $f$ - feed per revolution; $a_{P}$ - depth of cut / turning.

Next, productivity is depending on the process power generation per part volume change. High productive tools are resistant against mechanical and thermal loads, demanding higher process power reserve.

$M-M_{L}=J \times \frac{d \omega}{d t} ;(15)$ where: $\mathrm{M}$ - torque; $\mathrm{ML}-$ load torque; $\mathrm{J}$ - moment of inertia; $\omega$ - rotational speed.

Balanced power reserve $\mathrm{M}-\mathrm{M}_{\mathrm{L}}$ and motion profile $\frac{\mathrm{d} \omega}{\mathrm{dt}}$ influence the process work (cutting, forming) via drive control parameters velocity, acceleration and jerk. Those process consumes less energy, which has a minimum of the product (process force $\times$ distance). Those machine tool consumes less energy, which has a minimum of the product (drive force $\times$ distance) for the applied process demand. Process work (energy) consumption is the integral of power consumption over the used process time. Drive control setup results in an optimal motion profile for the process velocity, optimal drive force or torque for the process force or torque and optimal drive power over process time. Velocity changes were tested for step response and system oscillations at natural frequencies higher than process frequencies (escaping drive resonances).

$P_{C}=F_{C} \times v_{C} ;(16)$

where: $F_{C}$ - cutting force; $v_{C}-$ cutting velocity; $P_{C}-$ cutting power / turning process. The fracture model determines the physical structure of the process - the physical model of cutting (the physical process of plastic deformation and fracture) and shear stresses $\tau_{s}$, which determine the dislocation shift, are equal to: $\tau_{s}=\tau_{x y}=\frac{F_{s}}{S_{s}}$. The shift occurs when the tangential stresses and active forces on the part and tool side are equal. In the considered case, the cutting force structure is important, which can be written as: $\bar{F}_{s}=$ $\tau_{s} \times K_{s}$ where the $K_{s}$ coefficient is determined by the considered cutting model and depends on the type and quantity of parameters taken into account (geometric linear and angular, physical properties, e.g. friction type, etc.) and the degree of their detailing. At the same time, the cutting force operation is determined by the cutting force and cutting speed. Consequently, the following relations can be written down:

$\tau_{s}=\frac{F}{A}=\frac{F \times \frac{L}{\tau}}{A \times \frac{L}{\tau}}=\frac{F \times v}{\frac{V}{\tau}}=\frac{P}{Q}=\frac{W}{V}$,

where $\mathrm{F}$ is force; $\mathrm{A}$ is area; $\mathrm{L}$ is length (cutting motion); $\tau$ is time; $\mathrm{V}$ is volume; $\mathrm{V}$ is speed; $\mathrm{P}$ is power; $\mathrm{Q}$ is specific capacity; $W$ is energy; $\tau_{s}=\frac{W}{V}$ is specific energy capacity. From this conceptual dependence follow the values of energy ranges required for cutting different materials under different cutting conditions (table 7).
Tab. 7: Values of energy ranges required for cutting different materials under different cutting conditions.

\begin{tabular}{|l|l|l|l|}
\hline $\begin{array}{l}\text { Chip } \\
\text { removal } \\
\text { range }\end{array}$ & $1 \mathrm{~nm}: 0.1 \mu \mathrm{m}$ & $0.1 \mu \mathrm{m}: 10 \mu \mathrm{m}$ & $10 \mu \mathrm{m}: 1 \mathrm{~mm}$ \\
\hline $\begin{array}{l}\text { Defects/ } \\
\text { inclusions }\end{array}$ & Point defect & $\begin{array}{l}\text { Displace- } \\
\text { ment/ crack }\end{array}$ & $\begin{array}{l}\text { Crack/ inter } \\
\text { crystal } \\
\text { boundary }\end{array}$ \\
\hline $\begin{array}{l}\text { Material } \\
\text { destruction } \\
\text { type }\end{array}$ & Atomic cluster & $\begin{array}{l}\text { Sub- } \\
\text { crystalline }\end{array}$ & $\begin{array}{l}\text { Multi- } \\
\text { crystalline }\end{array}$ \\
\hline $\begin{array}{l}\text { Brittle } \\
\text { fracture } \\
\text { resistance } \\
\text { limit }\end{array}$ & $\begin{array}{l}10^{4} \mathrm{~J}^{3} / \mathrm{m}^{3}: 10^{3} \\
(\text { atomic crack) }\end{array}$ & $\begin{array}{l}10^{3} \mathrm{~J}^{3} / \mathrm{m}^{3}: 10^{2} \\
\mathrm{~J} / \mathrm{m}^{3} \\
(\mathrm{micro} \text { cracks) }\end{array}$ & $\begin{array}{l}10^{2} \mathrm{~J} / \mathrm{m}^{3}: 10^{1} \\
(\text { fragile crack })\end{array}$ \\
\hline $\begin{array}{l}\text { Shear } \\
\text { resistance } \\
\text { limit (shear) }\end{array}$ & $\begin{array}{l}10^{4} \mathrm{~J} / \mathrm{m}^{3} \\
(\text { atomic } \\
\text { displacement) }\end{array}$ & $\begin{array}{l}10^{3} \mathrm{~J} / \mathrm{m}^{3}: 10^{2} \\
(\mathrm{slip} \mathrm{offset})\end{array}$ & $\begin{array}{l}10^{2} \mathrm{~J} / \mathrm{m}^{3}: 10^{1} \\
\mathrm{~J} / \mathrm{m}^{3} \\
(\text { shear strain) }\end{array}$ \\
\hline \multicolumn{2}{|l|}{} & \\
\hline
\end{tabular}

The motion system can be interpreted as a closed control loop [DIN IEC 60050-351:2014-09], characterized by a control error $\mathrm{e}=\mathrm{w}-\mathrm{y}_{\mathrm{w}}$, where $\mathrm{w}$ is the reference variable, and $y_{w}$ - the controlled variable. The CNC part program controls path velocity for part cutting operations targeting the precision of the sequence of motion (control error e), but not the energy efficiency (wear, heat, noise generation), or stress limits in the electromechanical system (power gradient, risk of resonances). Energy efficiency $\varepsilon$ is also introduced as an integral energy characteristic of the sequence of motion. The energy efficiency $\varepsilon$ is the ration of energy output to energy consumed during the cycle time $T_{c}$. [VDI/VDE 3547:2003]

$\varepsilon=\frac{\int_{0}^{T} c p_{L(t) d t}}{\int_{0}^{T c} p_{e(t) d t}}$

where $T_{c}$ cycle time of a periodic motion, or a duration of a sequence of motion, $p_{e}(t)$ electrical power input, function of time, $p_{L}(t)$ power output of the process, function of time. Other than the efficiency $\eta$, which is defined for one specific operating point, the energy efficiency $\varepsilon$ characterizes the overall energy balance of one working cycle or one single motion. The energy efficiency $\varepsilon$ is therefore a criterion for assessing the quality of sequences of motion.

Manufacturing requires defined work piece geometry and surface quality and different material properties for exchangeability in component assembly to systems. Power reserve is providing system stiffness, tool wear per shape and material property change. Motion profiles contain contour control deviations under process loads, vibration amplitudes at natural frequencies, leading to machine tool errors and work piece deviations. Energy consumption per quality value is a function of partial power consumption over process chain time, especially when a precision limit leads to rough and fine operations.

Furthermore, the motion profile over process load influences the technological performance through velocity, acceleration, and jerk for short process time, depending on high-performance drives, encoders and position and/or force control systems. Objective criteria for the comparative assessment of motion systems (which fulfil technical functions), are precision of the sequence of motion, energy efficiency, stress limits in the electromechanical system [VDI/VDE 3547:2003]. Process loads define the machine tool geometry and dimension in order to resist deformation or wear with power reserve. A motion profile consists of 
axes position, orientation sequences per kinematic chain and axis stroke. Component energy efficiency is a function of partial power consumption over process time and in stand-by.

\subsection{Matter resource consumption $\mathrm{E}_{\mathrm{e}}^{\mathrm{m}}$}

Matter resource consumption $E_{e}^{m}$ characterizes the degree of change of properties, qualities, processes, phenomena productivity is the rate of change of properties, conditions, structure of matter or resource. Therefore, it is also necessary, from the point of view of the system approach, to distinguish between the following concepts of "productivity": Physical process efficiency, technological productivity, achievable productivity, real productivity, effective productivity, energy efficiency, system productivity, structural productivity, etc.

Then in (9) the $E_{e}^{m}$ component, characterizing the rate of change of material properties, will be determined by the components of the physical process execution time and the provision time and/or change time of the spatial-temporal position/state of the physical process application. This includes the resource required to change the position/state in the space of the physical process vector), providing this process during the considered or established period of time, for example, the cycle of manufacturing of the part or the cycle of operation of the equipment or the change of the equipment, etc.

Taking into account that the theoretical performance of the physical process at the input of $E_{i}$ system is the value of inversely proportional to the time of its execution, and the real performance of $\mathrm{E}_{j}$. At the output of the system is the value of inversely proportional to the time of its real, actual execution, then in (9), (10) and (11) the value of $\mathrm{E}_{\mathrm{us}}^{\mathrm{f}}$ and $\left(E_{u s}^{f}\right)^{r}$ will characterize, respectively, the characteristics of time and their losses:

$E_{e}^{m}=\frac{E_{j}}{E_{i}} \div \frac{\frac{1}{\left(E_{u s}^{f}\right)^{r}}}{\frac{1}{E_{u s}^{f}}} \div \frac{E_{u s}^{f}}{\left(E_{u s}^{f}\right)^{r}}$

Consequently, the time losses over the time period in question will be due to the following types (groups) of losses:

- $\quad$ before processing (physical process);

- in the process of processing (physical process execution);

- $\quad$ after processing (to assess the quality of the result of the physical process and other changes in the spatial and temporal position/state of the physical process of application).

Obviously, from (8) and (9) follows the estimation of Overall Equipment Effectiveness OEE, which is a special case of the $\mathrm{E}_{\mathrm{e}}^{\mathrm{m}}$ component. In fact, the OEE-Index is the product of three probabilities of events, each of which is equal to the ratio of the event's completion time to the total event time.

At the same time, the overall integrated assessment in all cases will correspond to the integrated efficiency from table 1. The number and types of individual partial indicators characterizing different properties of efficiency, can be applied or obtained, as illustrated in table 1 and determined by the goals and objectives of this analysis, as applied to the type of equipment, technological or production process.

Then, the OEE-Index in the component designations in (11) will be equal:

$\mathrm{U}_{\mathrm{e}}=\frac{E_{u s}^{f}}{\left(E_{u s}^{f}+\left(\delta E_{k, k}\right)_{u s}^{f}+\left(\delta E_{k, n}\right)_{u s}^{f}+\left(\delta E_{k, k}\right)_{c h}^{f}+\left(\delta E_{k, n}\right)_{c h}^{f}\right)}$ or
$\mathrm{U}_{\mathrm{e}}=\frac{E_{u s}^{f}}{E_{u s}^{f}+\left(\delta E_{k, k}\right)_{u s}^{f}+\left(\delta E_{k, n}\right)_{u s}^{f}+\left(\delta E_{k, k}\right)_{c h}^{f}+\left(\delta E_{k, n}\right)_{c h}^{f}}=\frac{E_{u s}^{f}}{E_{u s}^{f}+\left(\delta E_{k, k}\right)_{u s}^{f}} \times$ $\frac{E_{u s}^{f}+\left(\delta E_{k, k}\right)_{u s}^{f}+\left(\delta E_{k, n}\right)_{u s}^{f}}{E_{u s}^{f}+\left(\delta E_{k, k}\right)_{u s}^{f}+\left(\delta E_{k, n}\right)_{u s}^{f}+\left(\delta E_{k, k}\right)_{c h}^{f}+\left(\delta E_{k, n}\right)_{c h}^{f}}=$ $\frac{E_{u s}^{f}+\left(\delta E_{k, k}\right)_{u s}^{f}+\left(\delta E_{k, n}\right)_{u s}^{f}}{E_{u s}^{f}+\left(\delta E_{k, k}\right)_{u s}^{f}+\left(\delta E_{k, n}\right)_{u s}^{f}+\left(\delta E_{k, k}\right)_{c h}^{f}+\left(\delta E_{k, n}\right)_{c h}^{f}} \times$ $\frac{E_{u s}^{f}+\left(\delta E_{k, n}\right)_{u s}^{f}}{E_{u s}^{f}+\left(\delta E_{k, k}\right)_{u s}^{f}+\left(\delta E_{k, n}\right)_{u s}^{f}} \times \frac{E_{u s}^{f}}{E_{u s}^{f}+\left(\delta E_{k, k}\right)_{u s}^{f}}$

So, availability in reliability theory and reliability engineering, the term availability is defined as the degree to which a system, subsystem or equipment is in a specified operable and committable state at the start of a mission, when the mission is called for at an unknown, i.e. a random, time. Availability is the proportion of time a system is in a functioning condition [ISO 22400-2:2014]:

$\mathrm{V}_{\mathrm{T}}=\left(1-\frac{\mathrm{T}_{\mathrm{T}}}{\mathrm{T}_{\mathrm{B}}}\right) * 100 \% ; \quad$ (21) where: $\mathrm{T}_{\mathrm{T}} \quad$ - technical downtime; $\mathrm{T}_{\mathrm{B}}$ - occupied time; $\mathrm{V}_{\mathrm{T}}$ - technical availability. In this methodology we apply the following form:

$\mathrm{V}_{\mathrm{T}}=\frac{\mathrm{T}_{\mathrm{B}}-\mathrm{T}_{\mathrm{T}}}{\mathrm{T}_{\mathrm{B}}}=\frac{\mathrm{T}_{\mathrm{T}}+\delta \mathrm{T}_{\mathrm{T}}-\mathrm{T}_{\mathrm{T}}}{\mathrm{T}_{\mathrm{T}}+\delta \mathrm{T}_{\mathrm{T}}}=\frac{\delta \mathrm{T}_{\mathrm{T}}}{\mathrm{T}_{\mathrm{T}}+\delta \mathrm{T}_{\mathrm{T}}}$

In this case it follows that the indicator of the reference frames being compared is also obtained as a special case (20). Resource life time reserve per process load is a function of component material properties, process loads, motion profile and exploitation conditions.

Applied methodology on resource consumption classes of machine tools is available for manufacturers and customers in order to analyze and optimize their resource use during lifetime. Machine tool specifications are available for calculations in design and system development phases. Machine tool measurements are available for value analysis in set-up and use phase.

\subsection{Information consumption $E_{e}^{i}$}

Information consumption $E_{e}^{i}$ characterizes the degree of conformity of properties, qualities, processes, phenomena. In the energy information system under consideration (Fig.1), the total amount of information consists of information about the product (product, parts) and its properties $I_{w}$, physical process $I_{f}$ and process control $I_{c}$.

$I_{0}=\sum_{k=1}^{K} I_{w}+\sum_{m=1}^{M} I_{f}+\sum_{n=1}^{N} I_{c}$

The amount of information is determined by a known relationship as follows:

$I=-\sum_{i=1}^{N} p_{i} \times \log _{2} p_{i} \quad(24)$

where I - number of information; $\mathrm{N}$ - number of possible events; $p_{i}$ - probability of individual events. If the probability of occurrence of individual events is the same and they form a complete group of events, i.e. $\sum_{i=1}^{N} p_{i}=1$, the formula is transformed into the formula of R. Hartley: $I=\log _{2} P$ or $I=$ $K \times \ln (P)$. The amount of information that characterizes the point $I_{p}$, the line $I_{L}$, the surface $I_{S}$ or the volume $I_{V}$ is equal, respectively:

$I_{P}=\log _{2}\left(\frac{L}{\Delta x}\right)=-\log _{2}\left(\varepsilon_{c}\right), I_{L}=-3 \times\left(\frac{1}{\varepsilon_{c}}\right) \log _{2}\left(\varepsilon_{c}\right)$,

$I_{S}=-3 \times\left(\frac{1}{\varepsilon_{c}}\right)^{2} \log _{2}\left(\varepsilon_{c}\right), I_{S}=-3 \times\left(\frac{1}{\varepsilon_{c}}\right)^{3} \log _{2}\left(\varepsilon_{c}\right)$.

where $\varepsilon_{c}=\frac{\Delta x}{L}$ is a comparative error, $L$ is a characteristic size.

So, for example, when specifying the position of a point with a characteristic size of $1 \mathrm{~m}$ and a comparative error of $10^{-6}$ $\mathrm{m}$, we obtain, $I_{P}=20, I_{L}=60 \times 10^{6}, I_{S}=60 \times 10^{12}, I_{V}=$ 
$60 \times 10^{18}$. Therefore, the combination of analogue and numerical information is most often used to create equipment, which allows you to significantly reduce the required volume of information conversion. In particular, in metal-cutting machines, the guide movements are, from the point of view of information, the volume of information that is enclosed in the line, which with the accuracy of movement in $1 \mu \mathrm{m}$ corresponds to the amount of information equal to $I_{L}=60 \times 10^{6}$. On this basis, analog and other data carriers are required to repeatedly use and store them for a given time period, as well as the inadmissibility of its loss during operation under external and internal influences on the quantity and quality of transmitted and converted information.

Accuracy of processes, equipment and manufactures is defined by level of conformity or degree of approximation of real properties, parameters and characteristics of a product (an object, a product or a detail) to its image (to information, geometrical, technological) - nominal, set or ideal value. Changes and mutual relationships of the properties of respective images characterize and define their qualitative and quantitative parameters and characteristics. Therefore, it is necessary to distinguish between the following concepts of "accuracy": accuracy of the product, accuracy of the physical process, physically (realistically) achievable accuracy, technological accuracy, accuracy of the system, structural accuracy, effective accuracy, etc.

Then the components $E_{u s}^{f}$ and $E_{c h}^{f}$ will be defined by the information about the physical process and its management and the information about the product properties (denominator $\left(E_{u s}^{f}\right)^{r}$ and equipment (numerator) $E_{c h}^{f}$, respectively, by (11). Consequently, the third component determines the efficiency of the accuracy parameter.

\subsection{Application to machine tools}

A common approach to the assessment of the effectiveness of processes, equipment and productions in terms of community assessment methodology, allows us to consider them as energy-model, in which the conversion of all shapes and types of energy, matter and information. This approach allows us to consider the concept of efficiency as the relative efficiency of the collection of all kinds of conversion elements of the system. Then, using the analogy of building structures in energy efficiency, information efficiency, productivity, accuracy, obtained a general (integral) expression assess the Integral Manufacturing Efficiency of new physical processes and production technologies, which are based on new physical phenomena and processes of transformation of matter, energy and information.

A comparison between machine tool specification values and classified values is required. The best available technology or best available techniques is the technology approved by legislators or regulators (e.g. CECIMO) for meeting output standards for a particular process.

Resources for work piece material properties, power reserve and motion profile are included in the machine tool specifications.

For example, parameters of a 3 -axis machining centre HEC400D regarding energy consumption $E_{e}^{e}$ follow (11) and include technological process values for steel milling:

Work piece dimensions: $400 \times 400 \times 400 \mathrm{~mm}^{3}$, axis travel X650 mm, Y650 mm, Z680 mm, B+/-95 .

Work piece material: C45E 1.1191, strength $\mathrm{Rm} 800$ $\mathrm{N} / \mathrm{mm}^{2}$, specific cutting force $\mathrm{k}_{\mathrm{c}}=3160 \mathrm{~N} / \mathrm{mm}^{2}$.

Tool diameter: shaft milling tool d $35 \mathrm{~mm}, 5 \mathrm{HM}$, chip thickness $h_{z}=0.08 \mathrm{~mm}, \omega$ - rotational speed $n=1090 \mathrm{rpm}$; $v_{C}$
- cutting velocity $120 \mathrm{~m} / \mathrm{min} ; F_{C}-$ cutting force $=30$ $\mathrm{mm}^{*} 0.08 \mathrm{~mm} \times 3160 \mathrm{~N} / \mathrm{mm}^{2}=7500 \mathrm{~N}$; cutting process power $P_{C}=F_{C} \times v_{C} ;=7500 \mathrm{~N} \times 2 \mathrm{~m} / \mathrm{s}=15 \mathrm{~kW}<24 \mathrm{~kW}$ spindle power.

$v$ - cutting axis speed $0.15 \mathrm{~m} / \mathrm{min} ; \mathrm{f}$ - feed per revolution $0.4 \mathrm{~mm}$; ap - depth of cut / milling $30 \mathrm{~mm}, M R R=v \times f \times$ $a_{P} ; \mathrm{MRR}=150 \mathrm{~mm} / \mathrm{min} \times 0.4 \mathrm{~mm} \times 30 \mathrm{~mm}=1800$ $\mathrm{mm}^{3} / \mathrm{min}$.

Load torque $\mathrm{ML}=\mathrm{F}_{\mathrm{c}} \times \mathrm{d} / 2=7500 \mathrm{~N} \times 0.0175 \mathrm{~m}=132 \mathrm{Nm}$; $\mathrm{M}-$ torque $=140 \mathrm{Nm} ; M-M_{L}=J \times \frac{d \omega}{d t}$;

Cutting energy $W_{C}=\int P_{C} \times d t ; P_{C}-$ cutting power, $\mathrm{t}-$ process time.

Machine centre availability $A=0.95$.

Machine centre position accuracy $\mathrm{Pa}=0.005 \mathrm{~mm}$.

A more detailed example of the quantitative determination of estimates of integral indicator of resource efficiency $E_{r e}$ for metal cutting processes (matter resource consumption $E_{e}^{m}$ and information consumption $E_{e}^{i}$ ), as well as the application of the methodology for the comparison of cutting efficiency and additive technologies are given in [Kuznetsov 2017].

Technological requirements define the resource consumption class, following table 2 and table 3 . Following table 3 , a comparison of a 3 -axis machining centre to best available technology results in resource consumption class $\mathrm{N}^{\circ} 2$ of machining centres. This follows from the above machine tool data in the resource efficiency calculation and the evaluation indicators will be determined:

$E^{i}=\left(5^{2}+5^{2}+5^{2}\right)^{0.5} / 10=0.866$ at a given accuracy of $10 \mu \mathrm{m}$ and positioning accuracy $\mathrm{Pa}_{\mathrm{a}}=5 \mu \mathrm{m}$;

$\mathrm{E}^{\mathrm{m}}=1800 / 1800=1$, because the cutting performance is $1800 \mathrm{~mm}^{3} / \mathrm{s}$, and its $\mathrm{E}^{\mathrm{e}}=(15+2) /(24 \times 0,6+4)=0,924$, because the cutting energy is defined as $15 \mathrm{~kW}$ and the servo drive power is $4 \mathrm{~kW}$. Consequently, resource efficiency $E_{r e}$ will be equal to $E_{r e}=0.866 \times 1 \times 0.924=0.8$.

Manufacturing demand for higher the integral indicator of resource efficiency $E_{r e}$ or lower part manufacturing costs may result in new targets compared to best available technology.

\subsection{Manufacturing costs}

Manufacturing cost is the sum of costs of all resources consumed in the process of making a product. The manufacturing cost is classified into three categories: direct materials cost, direct labour cost and manufacturing overhead. Value creation per energy costs is a function of process effectiveness, machine and tool life time costs, and part manufacturing time. Overall Equipment Effectiveness is a key performance indicator influencing manufacturing costs derived from resource efficiency of machine tools.

How a human is involved in a full-scale solution? European manufacturing sector consists dominantly of small and medium enterprises with human operators and programmers of CNC machine tools. A higher automation degree in machine tools leads to less human involvement and personnel costs.

\section{SUMMARY}

Integrated methodology for synthesis, design, dimensioning, test and evaluation of for manufacturing systems, processes and environment becomes digital measureable and comparable.

Development trends and engineering methods aimed at lowest resource consumption / losses and part 
manufacturing costs bases on the classification of machine tools according to their effectiveness.

The proposed methodology on resource consumption classes of machine tools is answering the scientific question on sustainability: which technological requirements and machine functionalities to machine tool characteristics lead to their lowest resource consumption / losses and part manufacturing costs?

Together, Resource efficiency class (energy, matter, information) and OEE class (manufacturing costs) are Key Performance Indicators for sustainable machine tools.

The proposed integrated methodology for synthesis, design, dimensioning, test and evaluation of for manufacturing systems, processes and environment is developing trends and engineering methods aimed at lowest resource consumption / losses and part manufacturing costs. The human involvement in the evaluation, decision making and operation process of industrial applications during whole life cycle is targeting. It is a tool for analysis, forecasting, development, etc. to achieve the target value. It is obvious that these efficiencies can have different directions; hence the next task is a rational choice assessment, followed by an optimization.

\section{REFERENCES}

[Denkena 2018] Scientific demand in setting development trends for manufacturing systems, processes and environment; Progress Report on STC-M Keynote Paper 2020 "Energy Efficient Machine Tools" by B. Denkena. Internet: https://www.cirp.net/scientific-groups/stcscientific-technical-commitees/stc-m-machines/1076-stcm-2018-annual-report.html

[DIN IEC 60050-351:2014-09] International electrotechnical vocabulary - Part 351: Control technology; Beuth Verlag, 2014, 381p. https://dx.doi.org/10.31030/2159569

[DIN 8580:2003-09] Fertigungsverfahren; Deutsche Norm; DIN Deutsches Institut für Normung e. V., Beuth Verlag GmbH, 10772 Berlin; September 2003

[Gamberini 2017] Gamberini R., Galloni L., et al.: On the Analysis of Effectiveness in a Manufacturing Cell: A Critica Implementation of Existing Approaches.27th International Conference on Flexible Automation and Intelligent Manufacturing, FAIM2017,27-30 June 2017, Modena, ItalyProcedia Manufacturing 11 ( 2017 ) 1882 - 1891.

[GOST R 54 430-2011] (State Standard): Metal- and Woodworking Equipment; Measures of Energy Efficiency; Nomenclature; Methods of Parameter Determination and Standardization, 2012. (PDF)

[Götze 2012] Götze, U., Koriath, H.-J., et al.: Integrated methodology for the evaluation of the energy- and costeffectiveness of machine tools. In: CIRP Journal of Manufacturing Science and Technology 5 (2012), Nr.3, S.151-163

http://dx.doi.org/10.1016/j.cirpj.2012.04.001

[Grigor'ev 2014] Grigor'ev, S.N.; Kuznetsov, A.P., et al.: Classification of metal-cutting machines by energy efficiency. In: Russian engineering research 34 (2014), No.3, pp.136-141

http://dx.doi.org/10.3103/S1068798X14030058)

[ISO 14955-1:2017] Machine tools - Environmental evaluation of machine tools - Part 1: Design methodology for energy-efficient machine tools; ISO/TC 39; April 2012, $63 \mathrm{p}$.

[ISO 22400-2:2014] Automation systems and integration -Key performance indicators (KPIs) for manufacturing operations management -- Part 2: Definitions and descriptions. ISO/TC184, January 2014, 60 pp.

[Kuznetsov 2016_1] Kuznetsov, A.P., Blau, P., et al.: Criteria for Energy-Efficiency of Technological Processes, Technological Machines and Production Engineering. In: Procedia CIRP 46 (2016), S.340-343, DOI: http://dx.doi.org/10.1016/j.procir.2016.04.002

[Kuznetsov 2016_2] Kuznetsov, A.P., Koriath, H.-J.: A new systematic approach to the description of processes and their Classification. 14th Global Conference on Sustainable Manufacturing, GCSM 3-5 October 2016, Stellenbosch, South Africa. In: Procedia Manufacturing 8 (2017) 199 206. (Doi: 10.1016/j.promfg.2017.02.025)

[Kuznetsov 2017] Kuznetsov A.P., Koriath H.-J., et al.: Comparative Integrated Manufacturing Efficiency in Production Engineering. The 50th CIRP Conference on Manufacturing Systems CMS 2017; Procedia CIRP 63 (2017) 527 - 532, DOI: 10.1016/j.procir.2017.03.135

[Kuznetsov 2018] Kuznetsov, A.P., Koriath, H.-J., et al.: Equivalence assessment method for the resource efficiency of equipment, technologies and production systems. In: Procedia manufacturing 21 (2018), S.525-532, DOI: http://dx.doi.org/10.1016/j.promfg.2018.02.153

[Sato 2018] Sato R., Shirase K., et al.: Energy Consumption of Feed Drive Systems Based on Workpiece Setting Position in Five-Axis Machining Center. Journal of Manufacturing Science and Engineering; ASME, February 2018, Vol. 140 / 021008, pp. 1-7; DOI: 10.1115/1.4037427

[Schudoleit 2015] Schudoleit, T., Züst S., et al.: Methods for evaluation of energy efficiency of machine tools. Energy 93 (2015), Elsevier Ltd., p. 1964-1970, http://dx.doi.org/10.1016/j.energy.2015.10.074

[Schudoleit 2016] Schudeleit T., Züst S., et al.: The Total Energy Efficiency Index for Machine Tools, Energy, 2016, DOI http://dx.doi.org/10.1016/j.energy.2016.02.126, Volume 102, Issue 1, Pages 682--693

[Varisco 2018] Varisco M. et al. KPIs for Manufacturing Operations Management: driving the ISO22400 standard towards practical applicability / IFAC PapersOnLine 51-11 (2018) 7-12

[VDI 2206:2004] Design methodology for mechatronic systems; VDI June 2004, 118 p.

[VDI/VDE 3547:2003] Assessment of quality of motion systems and controlled sequences of motion; VDI June 2003, $26 \mathrm{p}$

[Yoon 2015] Yoon H.S., Kima E.S. et al.: Towards greener machine tools - A review on energy saving strategies and technologies. Renewable and Sustainable Energy Reviews 48 (2015) Elsevier Ltd. p. 870-891

[Zhou 2016] Zhou, L., Li J., et al.: Energy consumption model and energy efficiency of machine tools: a comprehensive literature review. Journal of Cleaner Production 112 (2016) Elsevier Ltd., p. 3721 -3734 